\title{
Internalized stigma and its correlates among justice- involved individuals with mental illness
}

\author{
Nikhil Tomar ${ }^{\mathrm{a}}$ (D), Lauren Brinkley-Rubinstein ${ }^{\mathrm{b}}$, Marilyn Ann Ghezzi ${ }^{\mathrm{c}}$, \\ Tonya Bloomer Van Deinsec, Stacey Burgin ${ }^{c}$, and Gary Steven Cuddeback ${ }^{c}$ \\ aDepartment of Occupational Therapy, University of New Hampshire, Durham, New Hampshire, \\ USA; ${ }^{\mathrm{b}}$ Department of Social Medicine, University of North Carolina at Chapel Hill, Chapel Hill, \\ North Carolina, USA; 'School of Social Work, University of North Carolina at Chapel Hill, Chapel \\ Hill, North Carolina, USA
}

\begin{abstract}
In the United States, the number of justice-involved individuals living with mental illnesses is large and growing; however, there is little information about internalized stigma experienced by this population. To address this gap, we assessed internalized stigma and its relationship with symptomatology and demographic and clinical characteristics among 108 probationers with severe mental illnesses. More than third of the sample reported high levels of internalized stigma, and more than half of the sample reported high scores on alienation and social withdrawal subscales. There was a positive and significant correlation between symptomatology and internalized stigma. Interventions to address internalized stigma among justice-involved people with mental illnesses are needed.
\end{abstract}

\section{KEYWORDS}

Probation; internalized stigma; psychiatric symptomatology; social withdrawal; alienation

\section{Introduction}

Breaking a law in the United States can place an individual on probation, which is defined as "a court-ordered period of correctional supervision in the community, generally as an alternative to incarceration. In some cases, probation can be a combined sentence of incarceration followed by a period of community supervision" (Bureau of Justice Statistics, 2015, p. 2). In the United States (US), approximately 6.7 million individuals are under supervision of the correctional system with about $56 \%$ on probation (Kaeble \& Glaze, 2016). Among those on probation, 16-27\% are estimated to experience a mental illness (Crilly, Caine, Lamberti, Brown, \& Friedman, 2009; Ditton, 1999). Compared to probationers without mental illnesses, probationers with mental illnesses have higher recidivism rates and can experience the negative intersection of stigma related to both mental illness and justice involvement, which likely exacerbates the challenges they face 
in realizing optimal mental health and criminal justice outcomes (Crilly et al., 2009; Ditton, 1999; Skeem, Eno Louden, Manchak, Vidal, \& Haddad, 2009; Skeem, Manchak, \& Peterson, 2011).

Evidence suggests that, based on stigmatizing views related to mental illness, probation officers might perceive probationers with mental illnesses as high-risk offenders requiring more surveillance than usual, increasing the chances of revoking probation revocations or decisions to reincarcerate based on minor infractions of probation terms (Eno Louden, Skeem, Camp, \& Christensen, 2008; Eno Louden \& Skeem, 2013; Petersilia \& Turner, 1993). Further, probation officers may also choose more punitive responses to a violation committed by a probationer with a mental illness compared to a probationer without such a diagnosis within a similar risk category (Eno Louden, Manchak, Ricks, \& Kennealy, 2018). These are two examples of how revocations and/or recidivism among probationers with mental illnesses could be associated with stigmatizing attitudes among probation officers.

Stigma toward mental illness can be described as a social process that involves labeling and stereotyping socially undesirable attributes, which leads to prejudice and discrimination toward members of a non-normative group, such as individuals with mental illnesses (Corrigan, 2004; Link \& Phelan, 2001). Stigma toward mental illness can be categorized into multiple sub-constructs, such as enacted, public, structural, courtesy, or anticipated stigma (Pescosolido \& Martin, 2015). However, public and internalized stigma are two forms of stigma that continue to be studied and discussed more than other sub-constructs. There is also scarcity of reliable and valid measures that focus on assessing sub-constructs of stigma other than public and internalized.

Endorsement of prejudicial or ill-informed views by the public toward individuals with mental illnesses can be defined as public stigma (Corrigan, 2004; Link \& Phelan, 2001). Many individuals with mental illnesses endorse public devaluation of their own illnesses leading to internalization of public stigma, which can be termed as internalized stigma (Ritsher, Otilingam, \& Grajales, 2003). For instance, an individual with schizophrenia or bipolar disorder might be ashamed of or devalue himself or herself as an individual with a serious mental illness after being exposed to the inaccurate and/or demeaning portrayals of such diagnoses depicted in the media or during or after encountering stigmatizing notions while interacting with the public (Angermeyer \& Dietrich, 2006; Corrigan \& Rao, 2012; Wahl, 1992).

Internalized stigma among individuals with mental illnesses is associated with poor self-esteem, poor social connectedness, and poor service engagement (Boyd, Adler, Otilingam, \& Peters, 2014; Livingston \& Boyd, 2010; 
Oliveira, Carvalho, \& Esteves, 2016). Moreover, internalized stigma among individuals with mental illnesses can also limit health care seeking behavior, which can hinder timely access to mental health services (Corrigan, Druss, \& Perlick, 2014; Lannin, Vogel, Brenner, Abraham, \& Heath, 2016). In addition, internalized stigma is known to negatively influence self-esteem among individuals with mental illnesses, which can be detrimental to their quality of life in that self-esteem and quality of life are positively correlated (Mashiach-Eizenberg, Hasson-Ohayon, Yanos, Lysaker, \& Roe, 2013; Oliveira, Carvalho, \& Esteves, 2016).

Further, through its role in influencing self-esteem and quality of life, internalized stigma can also negatively influence psychiatric symptomatology. Indeed, there is evidence that internalized stigma is highly correlated with psychiatric symptom severity (Boyd et al., 2014; Livingston \& Boyd, 2010). This is of particular concern given evidence that internalized stigma is associated with poor quality of life and social relationships, which can further deteriorate psychiatric symptomatology and negatively impact criminal justice outcomes (Boyd et al., 2014; Livingston \& Boyd, 2010; Oliveira et al., 2016; Skeem et al., 2009, 2011).

Stigmatizing attitudes among mental health service providers can also negatively influence health care decision-making and possibly perpetuate internalized stigma among mental health consumers (Henderson et al., 2014; Monahan et al., 2005). For example, because of stigmatizing attitudes, mental health providers might use the threat of criminal sanctions or outpatient commitment to leverage psychiatric care adherence among individuals with mental illnesses (Monahan et al., 2005). Using such leverage, which is in antithesis to collaborative care, can perpetuate internalized stigma among mental health consumers by disempowering them to make decisions about their own care.

The existing literature on internalized stigma among justice-involved individuals with mental illnesses is limited to only a few studies (Boyd et al., 2014; Livingston, Rossiter, \& Verdun-Jones, 2011). More research is needed to understand the stigma experienced by this particularly vulnerable population. For example, Livingston and colleagues (2011) found no significant differences in internalized stigma among samples of non-justice and justice-involved people with mental illnesses; however, it is notable that close to one-third of the sample self-reported high levels of alienation (32\%) and discrimination experiences (36\%). To further contribute to research about internalized stigma among justice-involved people with mental illnesses, the purpose of this study is to assess internalized stigma among probationers with mental illnesses and examine the relationship between stigma and mental health symptomology and mental health service utilization. 


\section{Materials and methods}

\section{Design}

A cross-sectional design and data from a small-scale randomized controlled trial of specialty mental health probation in a southeastern state were used. Eligibility criteria for the study included: aged 18 years or older, a diagnosis of serious mental illness, no special probation caseloads (e.g., sex offender caseloads), and the ability to provide informed consent as assessed by research staff using a brief assessment. Diagnostic criteria for serious mental illness was assessed with the Mini-International Neuropsychiatric Interview (MINI) and qualifying diagnoses included: major depression (current), bipolar disorder, psychotic disorder, and/or posttraumatic stress disorder (PTSD). Trained research staff administered the MINI as part of study enrollment and baseline interview with probationers (Sheehan et al., 1998).

\section{Sample}

Probationers with mental illnesses were referred to the study by their probation officers. Members of the research team met with each participant privately to establish study eligibility, obtain consent and conduct baseline interviews. Ability to provide informed consent was confirmed with a brief assessment where participants were asked to recall the study's purpose, risks, activities, and protocol for withdrawing. All recruited participants provided informed consent. Baseline interviews included collecting demographic information and administering standardized measures of mental health functioning, relationship with probation officer, and internalized stigma.

Participation in the study was voluntary and participants could withdraw from the study at any time without negative consequences. Interviews were conducted with 108 probationers with serious mental illnesses between the months of October 2014 and February 2016. The study was approved by the Institutional Review Board at the (omitted to preserve anonymity).

The sample of probationers $(n=108)$ was, on average, $36.1(\mathrm{SD}=12.2)$ years of age and $46.3 \%(n=50)$ identified as female. Nearly $42 \%(n=45)$ identified as White and $41 \%(n=44)$ identified as African-American. Regarding education, 29.6\% (32) reported having less than a high school education, 38\% (41) reported having completed high school, 16.7\% (18) reported having some college experience, whereas the rest of the sample $(15.7 \%, n=17)$ reported having an associate or higher level college degree.

Bipolar disorder was the most common primary diagnosis (59.3\%, $n=64$ ), followed by major depression (26.9\%, $n=29)$, psychotic disorder 
(7.4\%, $n=8)$ and PTSD (6.5\%, $n=7)$. Participants had been on probation an average of $9.5(\mathrm{SD}=11.6)$ months and around $41 \%(n=44)$ of participants were on probation for the first time. Around 52\% $(n=56)$ of the sample reported being unemployed, 51\% $(n=55)$ reported no health insurance coverage, and $42 \%(n=45)$ reported no current mental health service use.

\section{Measures}

To assess internalized stigma, the Internalized Stigma of Mental Illness (ISMI) scale was used (Ritsher et al., 2003). The ISMI is a 29 -item measure with a four-point Likert scale (strongly disagree to strongly agree) response pattern with higher scores indicating higher levels of internalized stigma. A summed mean score of 2.5 or higher indicates high internalized stigma (Boyd et al., 2014; Ritsher et al., 2003). The ISMI has five sub-scales: alienation (perception of being an unaccepted member of society), stereotype endorsement (agreement with common stereotypes related to mental illness), discrimination experience (respondent's perception of his or her discriminatory treatment), social withdrawal (distancing of self from usual community or social activities), and stigma resistance (experiences of resisting endorsement of stigma) (Ritsher et al., 2003). The stigma resistance subscale was excluded from the analyses due to its low internal consistency reliability (Boyd et al., 2014). Excluding the stigma resistance subscale, the ISMI scale, has acceptable internal consistency reliability $($ alpha $=0.91$ ) and evidence of construct validity (Boyd et al., 2014; Ritsher et al., 2003).

The Symptom Checklist (SCL-10R), a shorter version of the widely-used Symptom Checklist-90 (SCL-90), is a 10-item measure of general distress and was used to assess mental health symptomatology (Rosen et al., 2000). The SCL-10R is reported to have reasonable internal consistency and evidence of convergent validity (Sheehan et al., 1998).

Current mental health service use was recorded during baseline interviews. Each study participant was asked, "Are you currently receiving mental health services, such as counseling or medication management?"

\section{Data analysis}

Descriptive and bivariate analyses were conducted. Scores on ISMI items were summed and averaged in order to establish how many in the sample reported high levels of internalized stigma according to the ISMI's proposed cutoff score (i.e., 2.5) (Boyd et al., 2014; Ritsher et al., 2003). Next, independent $\mathrm{t}$-tests were conducted to examine differences in ISMI scores based on mental health service use. Pearson correlations were computed to 
assess the correlation between ISMI and scores on the SCL-10R and Oneway Analysis of Variance (ANOVA) and $t$-tests were used to examine differences in ISMI scores based on demographic characteristics. Two-tailed tests were conducted with alpha set at .05 and all the analyses were conducted using SAS V9.3.

\section{Results}

The sample had an average ISMI total score of $55.6(\mathrm{SD}=13.3$, range $=$ $25-83)$ and a summed mean score of $2.31(\mathrm{SD}=0.5$, range $=1.04-3.46)$, excluding the stigma resistance subscale. More than third $(40.74 \%, n=44)$ of the sample reported high levels of internalized stigma (i.e., a score of 2.5 or higher on the ISMI). High internalized stigma was reported by $60.19 \%$ $(n=65)$ on the alienation subscale, $54.63 \%(n=59)$ on the social withdrawal subscale, $38.89 \%(n=42)$ on the discrimination subscale, $20.37 \%$ $(n=22)$ on the stigma resistance subscale, and $10.19 \%(n=11)$ on the stereotype endorsement subscale.

In addition, scores on the SCL-10 $(20.91, \mathrm{SD}=9.2)$ were significantly correlated with internalized stigma $(r=.57, p<.001)$ such that higher levels of stigma were associated with poorer psychiatric functioning. The mean score on SCL-10 for individuals reporting high internalized stigma was 26.54 (SD $=6.60)$ and $16.97(\mathrm{SD}=8.75)$ for those reporting low internalized stigma. However, no significant difference in the ISMI scores based on current mental health service use was found. That is, there were no differences in ISMI scores for mental health services users and non-users. There were also no differences in ISMI scores (total or among subscales) with respect to psychiatric diagnoses or any other demographic characteristics, such as gender, race, employment, health insurance coverage or education.

\section{Discussion}

This is one of the few studies to examine internalized stigma among probationers with mental illnesses in the U.S. Results suggest that more than third $(40.74 \%)$ of the sample self-reported high levels of internalized stigma and more than half of the sample reported high levels of alienation (60.19\%) and social withdrawal (54.63\%). This is notable in comparison to findings from other studies which demonstrated alienation and social withdrawal were markedly lower (32\% and $24 \%$ for feelings of alienation and social withdrawal, respectively (Boyd et al., 2014; Livingston et al., 2011).

Does justice involvement further intensify experiences of social withdrawal and alienation among individuals with mental illnesses? Further research is needed to answer this question; however, the findings presented herein raise a number of issues for practice, policy and research. For 
example, it could be that the cumulative effects of stigma related to justice involvement and mental illness may make it even more difficult for probationers with mental illnesses to maintain prosocial relationships with family and friends and, thus, may have a more difficult time realizing successful probation outcomes, such as obtaining employment, engaging in treatment or engaging in prosocial activities (Draine, Salzer, Culhane, \& Hadley, 2002; Hartwell, 2004; Moore, Stuewig, \& Tangney, 2016). This is of particular concern given evidence that prosocial engagements are often critical to foster successful probation outcomes but can be inhibited by internalized stigma, social withdrawal and perceptions of alienation among probationers with mental illnesses (Livingston \& Boyd, 2010; Livingston et al., 2011; Oliveira et al., 2016; Skeem et al., 2009; Skeem et al., 2011).

Psychiatric symptomatology was significantly correlated with internalized stigma in our sample, and these findings are consistent with those of other studies (Boyd et al., 2014; Livingston \& Boyd, 2010; Livingston et al., 2011). Although these findings cannot speak to whether mental illness symptomatology leads to higher internalized stigma, or vice-versa, severe symptomatology and higher internalized stigma can lead to negative psychiatric and criminal justice outcomes for probationers with mental illness (Livingston \& Boyd, 2010; Skeem et al., 2011). More research is needed regarding the role of internalized stigma and its direct and indirect influence on mental health and criminal justice outcomes for probationers with mental illnesses.

In addition, given the considerable level of internalized stigma found in this study, there is a need for more information about the social processes that contribute to high internalized stigma among some probationers. Evidence suggests that psychoeducation can help address stigma; however, no study has employed this strategy among probationers with mental illnesses (Henderson et al., 2014; Mehta et al., 2015; Tsang et al., 2016). It could be that psychoeducation among family members and probation officers could help reduce internalized stigma, alienation and social withdrawal among probationers by improving interactions between the probationers and others. Thus, more research is needed to assess the utility of psychoeducational interventions for probation officers (Tomar et al., 2017).

Besides psychoeducation, evidence regarding other interventions, such as Coming Out Proud and Narrative Enhancement and Cognitive Therapy, in addressing internalized stigma is emerging (Yanos, Lucksted, Drapalski, Roe, \& Lysaker, 2015; Yanos et al., 2019). Notably, such interventions have not yet been used to address internalized stigma among individuals with mental illnesses who are involved with the criminal justice system and this is an important area for future research. Further, while internalized stigma is dependent on stigma experienced on an interactional level, internalized stigma also shares reciprocal relationships with public and structural 
stigma, which places individuals living with serious mental illnesses in socially disadvantaged positions (Draine et al., 2002; Link \& Phelan, 2014; Livingston et al., 2011). Thus, a multi-faceted intervention approach is required to address internalized stigma for this population.

\section{Limitations}

Caution is warranted in generalizing findings from this study to other probation settings or individuals with mental illnesses, as the results of this study represent self-reported perceptions of stigma from a local sample of probationers with mental illnesses. Further, definition of serious mental illness was limited to diagnosis only and no measures of chronicity or functional disability were used. Data regarding substance use, which is a co-morbid diagnosis for many individuals with mental illnesses, were not collected, and thus, the findings do not account for the role of substance abuse diagnosis on the experiences of stigma. Due to lack of data, influences of crimes committed and history of incarceration on internalized stigma were also not assessed. Future research should examine the role of type of crime and criminal history with respect to internalized stigma among justice-involved individuals with mental illnesses.

Further, as highlighted earlier, we primarily explored internalized stigma among study participants; however, other types of stigma, such as enacted or anticipated stigma, were not explored in this study and require further research. A standardized measure to assess internalized stigma was used; however, the psychometric properties of the measure for this specific sample were not assessed. In addition, due to the cross-sectional design, causality and temporality between symptomatology and internalized stigma cannot be assessed; nevertheless, this study reports findings from a considerably-sized sample of probationers with mental illnesses and used standardized measures to assess diagnosis, symptomatology, and internalized stigma. To further advance the evidence, similar studies using these measures should be replicated in other probation settings.

\section{Conclusions}

The results of the present study suggest that justice-involved people with mental illnesses report high levels of internalized stigma, alienation and social withdrawal. Given the need to address issues at the intersection of justice-involvement and mental illness, more research is needed on interventions and strategies designed to counteract the negative influence of internalized stigma on community participation, mental health service utilization, and criminal justice outcomes. 


\section{ORCID}

Nikhil Tomar (D) http://orcid.org/0000-0002-3077-3341

\section{References}

Angermeyer, M. C., \& Dietrich, S. (2006). Public beliefs about and attitudes towards people with mental illness: A review of population studies. Acta Psychiatrica Scandinavica, 113(3), 163-179. doi:10.1111/j.1600-0447.2005.00699.x.

Boyd, J. E., Adler, E. P., Otilingam, P. G., \& Peters, T. (2014). Internalized Stigma of Mental Illness (ISMI) scale: A multinational review. Comprehensive Psychiatry, 55(1), 221-231. doi:10.1016/j.comppsych.2013.06.005.

Bureau of Justice Statistics (2015). Probation and parole in the United States, 2013. Washington, DC: US Department of Justice Bureau of Justice Statistics. Retrieved from https://www.bjs.gov/content/pub/pdf/ppus13.pdf.

Corrigan, P. (2004). How stigma interferes with mental health care. American Psychologist, 59(7), 614-625. doi:10.1037/0003-066X.59.7.614.

Corrigan, P. W., Druss, B. G., \& Perlick, D. A. (2014). The impact of mental illness stigma on seeking and participating in mental health care. Psychological Science in the Public Interest, 15(2), 37-70. doi:10.1177/1529100614531398.

Corrigan, P. W., \& Rao, D. (2012). On the self-stigma of mental illness: Stages, disclosure, and strategies for change. The Canadian Journal of Psychiatry, 57(8), 464-469. doi:10. 1177/070674371205700804.

Crilly, J. F., Caine, E. D., Lamberti, J. S., Brown, T., \& Friedman, B. (2009). Mental health services use and symptom prevalence in a cohort of adults on probation. Psychiatric Services, 60(4), 542-544. doi:10.1176/ps.2009.60.4.542.

Ditton, P. M. (1999). Special report: Mental health and treatment of inmates and probationers. Washington, DC: US Department of Justice, Bureau of Justice Statistics. Retrieved from https://www.prisonlegalnews.org/media/publications/bojs_mental_health_ and_treatment_of_inmates_and_probationers_1999.pdf.

Draine, J., Salzer, M. S., Culhane, D. P., \& Hadley, T. R. (2002). Role of social disadvantage in crime, joblessness, and homelessness among persons with serious mental illness. Psychiatric Services, 53(5), 565-573. doi:10.1176/appi.ps.53.5.565.

Eno Louden, J., Manchak, S. M., Ricks, E. P., \& Kennealy, P. J. (2018). The role of stigma toward mental illness in probation officers' perceptions of risk and case management decisions. Criminal Justice and Behavior, 45(5), 573-588. doi:10.1177/0093854818756148.

Eno Louden, J., \& Skeem, J. L. (2013). How do probation officers assess and manage recidivism and violence risk for probationers with mental disorder? an experimental investigation. Law and Human Behavior, 37(1), 22-34. doi:10.1037/h0093991.

Eno Louden, J. E., Skeem, J. L., Camp, J., \& Christensen, E. (2008). Supervising probationers with mental disorder: How do agencies respond to violations? Criminal Justice and Behavior, 35(7), 832-847. doi:10.1177/0093854808319042.

Hartwell, S. (2004). Triple stigma: Persons with mental illness and substance abuse problems in the criminal justice system. Criminal Justice Policy Review, 15(1), 84-99. doi:10. $1177 / 0887403403255064$.

Henderson, C., Noblett, J., Parke, H., Clement, S., Caffrey, A., Gale-Grant, O., ... Thornicroft, G. (2014). Mental health-related stigma in health care and mental healthcare settings. The Lancet Psychiatry, 1(6), 467-482. doi:10.1016/S2215-0366(14)00023-6. 
Kaeble, D. \& Glaze, (2016). Correctional Populations in the United States, 2015. Washington, DC: Bureau of Justice Statistics. Retrieved from https://www.bjs.gov/content/ pub/pdf/cpus15.pdf.

Lannin, D. G., Vogel, D. L., Brenner, R. E., Abraham, W. T., \& Heath, P. J. (2016). Does self-stigma reduce the probability of seeking mental health information? Journal of Counseling Psychology, 63(3), 351. doi:10.1037/cou0000108.

Link, B. G., \& Phelan, J. (2014). Stigma power. Social Science \& Medicine, 103, 24-32. doi: 10.1016/j.socscimed.2013.07.035.

Link, B. G., \& Phelan, J. C. (2001). Conceptualizing stigma. Annual Review of Sociology, 27(1), 363-385. doi:10.1146/annurev.soc.27.1.363.

Livingston, J. D., \& Boyd, J. E. (2010). Correlates and consequences of internalized stigma for people living with mental illness: A systematic review and meta-analysis. Social Science \& Medicine, 71(12), 2150-2161. doi:10.1016/j.socscimed.2010.09.030.

Livingston, J. D., Rossiter, K. R., \& Verdun-Jones, S. N. (2011). Forensic' labelling: An empirical assessment of its effects on self-stigma for people with severe mental illness. Psychiatry Research, 188(1), 115-122. doi:10.1016/j.psychres.2011.01.018.

Mashiach-Eizenberg, M., Hasson-Ohayon, I., Yanos, P. T., Lysaker, P. H., \& Roe, D. (2013). Internalized stigma and quality of life among persons with severe mental illness: The mediating roles of self-esteem and hope. Psychiatry Research, 208(1), 15-20. doi:10. 1016/j.psychres.2013.03.013.

Mehta, N., Clement, S., Marcus, E., Stona, A.-C., Bezborodovs, N., Evans-Lacko, S., ... Thornicroft, G. (2015). Evidence for effective interventions to reduce mental healthrelated stigma and discrimination in the medium and long term: A systematic review. British Journal of Psychiatry, 207(5), 377-384. doi:10.1192/bjp.bp.114.151944.

Monahan, J., Redlich, A. D., Swanson, J., Robbins, P. C., Appelbaum, P. S., Petrila, J., ... McNiel, D. E. (2005). Use of leverage to improve adherence to psychiatric treatment in the community. Psychiatric Services, 56(1), 37-44. doi:10.1176/appi.ps.56.1.37.

Moore, K. E., Stuewig, J. B., \& Tangney, J. P. (2016). The effect of stigma on criminal offenders' functioning: A longitudinal mediational model. Deviant Behavior, 37(2), 196-218. doi:10.1080/01639625.2014.1004035.

Oliveira, S. E., Carvalho, H., \& Esteves, F. (2016). Internalized stigma and quality of life domains among people with mental illness: The mediating role of self-esteem. Journal of Mental Health, 25(1), 55-61. doi:10.3109/09638237.2015.1124387.

Pescosolido, B. A., \& Martin, J. K. (2015). The stigma complex. Annual Review of Sociology, 41, 87-116. doi:10.1146/annurev-soc-071312-145702.

Petersilia, J., \& Turner, S. (1993). Intensive probation and parole. Crime and Justice, 17, 281-335. doi:10.1086/449215.

Ritsher, J. B., Otilingam, P. G., \& Grajales, M. (2003). Internalized stigma of mental illness: Psychometric properties of a new measure. Psychiatry Research, 121(1), 31-49. doi:10. 1016/j.psychres.2003.08.008.

Rosen, C. S., Drescher, K. D., Moos, R. H., Finney, J. W., Murphy, R. T., \& Gusman, F. (2000). Six and ten-item indexes of psychological distress based on the Symptom Checklist-90. Assessment, 7(2), 103-111. doi:10.1177/107319110000700201.

Sheehan, D. V., Lecrubier, Y., Sheehan, K. H., Amorim, P., Janavs, J., Weiller, E., ... Dunbar, G. C. (1998). The Mini-International Neuropsychiatric Interview (MINI): The development and validation of a structured diagnostic psychiatric interview for DSM-IV and ICD-10. Journal of Clinical Psychiatry, 59 (suppl 20), 22-33. 
Skeem, J., Eno Louden, J., Manchak, S., Vidal, S., \& Haddad, E. (2009). Social networks and social control of probationers with co-occurring mental and substance abuse problems. Law and Human Behavior, 33(2), 122-135. doi:10.1007/s10979-008-9140-1.

Skeem, J. L., Manchak, S., \& Peterson, J. K. (2011). Correctional policy for offenders with mental illness: Creating a new paradigm for recidivism reduction. Law and Human Behavior, 35(2), 110-126. doi:10.1007/s10979-010-9223-7.

Tomar, N., Ghezzi, M. A., Brinkley-Rubinstein, L., Wilson, A. B., Van Deinse, T. B., Burgin, S., \& Cuddeback, G. S. (2017). Statewide mental health training for probation officers: Improving knowledge and decreasing stigma. Health \& Justice, 5(1), 11. doi:10. 1186/s40352-017-0057-y.

Tsang, H. W., Ching, S. C., Tang, K. H., Lam, H. T., Law, P. Y., \& Wan, C. N. (2016). Therapeutic intervention for internalized stigma of severe mental illness: A systematic review and meta-analysis. Schizophrenia Research, 173(1-2), 45-53. doi:10.1016/j.schres. 2016.02.013.

Wahl, O. F. (1992). Mass media images of mental illness: A review of the literature. Journal of Community Psychology, 20(4), 343-352. doi:10.1002/1520-6629(199210)20:4<343::AIDJCOP2290200408>3.0.CO;2-2.

Yanos, P. T., Lucksted, A., Drapalski, A. L., Roe, D., \& Lysaker, P. (2015). Interventions targeting mental health self-stigma: A review and comparison. Psychiatric Rehabilitation Journal, 38(2), 171. doi:10.1037/prj0000100.

Yanos, P. T., Lysaker, P. H., Silverstein, S. M., Vayshenker, B., Gonzales, L., West, M. L., \& Roe, D. (2019). A randomized-controlled trial of treatment for self-stigma among persons diagnosed with schizophrenia-spectrum disorders. Social Psychiatry and Psychiatric Epidemiology, 54(11), 1363-1378. doi:10.1007/s00127-019-01702-0. 